J. Pestic. Sci., 30(3), 199-202 (2005)

|

Original Article

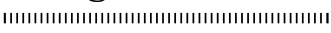

\title{
Effects of 6-Benzylaminopurine Applications on Bud Sprouting in Aralia elata Seem.
}

\author{
Hiroyuki SugIURA* and Takaaki AzUMA ${ }^{\dagger}$ \\ Fukushima College, Fukushima, 960-0181 \\ ${ }^{\dagger}$ Komagane-branch JA-Kamiina, Komagane Nagano, 399-2111
}

(Received January 20, 2005; Accepted April 4, 2005)

\begin{abstract}
This paper describes the effects of 6-benzylaminopurine (6BAP) on bud sprouting in mature Aralia elata Seem. trees. Greater bud sprouting was induced on cuttings from the upper parts than lower parts of the tree, with $50 \mathrm{mg} / 1$ if 6BAP than without. An average of 1.4 buds sprouted on the stumps not sprayed with 6-BAP after the trunks had been removed for the collection of cuttings. However, 3.4 buds sprouted on stumps receiving three applications at this concentration. From 2.9 to 3.5 buds sprouted when $50-200 \mathrm{mg} / 1$ of 6 BAP was sprayed onto trunks of three to four-year-old plants whose apical buds were removed, and 1.8 on trunks not sprayed with 6BAP. (C) Pesticide Science Society of Japan
\end{abstract}

Keywords: Aralia elata, 6-benzylaminopurine, lignified cutting, bud sprouting, stump, trunk.

\section{INTRODUCTION}

Japanese angelica trees (Aralia elata Seem.) are arbor plants of the Araliaceae family and grow wild in Northeast Asia. ${ }^{1)}$ They are picked in fields and mountains as edible wild plants, but they are also grown on farms. ${ }^{1)}$ Plants of the Araliaceae family are used all over the world as medicinal herbs and spices. ${ }^{2)}$ Labor costs are high for harvesting $A$. elata sprouts from the tops of trees, because the trees can grow up to four meters tall. Furthermore, it is difficult to harvest a large number of sprouts from $A$. elata trees because they grow few branches. A larger harvest would be possible if a number of cuttings were made from the stems of fall plants and buds formed on them. Less harvesting work would be necessary if the stems of the plants were cut to a lower height and buds sprouted on them. Tissue culture is used for the propagation of $A$. elata. ${ }^{3)}$ However, the production of seedling by tissue culture requires a large investment in facilities and labor. Bud sprouting is promoted by growth regulators, which increase branching, and a large number of sprouts can be harvested the following year in A. elata. Cytokinins are thought to control the differentiation of tissue in plants. ${ }^{4)}$ 6BAP is a cytokinin that induces morphological changes in chrysanthemum. ${ }^{5)}$

The effects of 6BAP on bud sprouting were studied for in-

\footnotetext{
* To whom correspondence should be addressed.

E-mail: hirosugiu2@tree.odn.ne.jp

(C) Pesticide Science Society of Japan
}

creased sprout harvesting in $A$. elata.

\section{MATERIALS AND METHODS}

\section{Plant Material}

The research field of the Myoukou Forest Horticulture Research Institute $(640 \mathrm{~m}$ above sea level) was used for all the experiments, which were conducted in 2004. Materials were collected from wild plants in the field.

\section{Effects of 6BAP on Sprouting of Lignified Cuttings (Experiment 1)}

Lignified stems $25-40 \mathrm{~cm}$ long were divided into three parts (top, 200-300 cm; middle, $80-160 \mathrm{~cm}$; bottom, 20-40 cm above the ground) as shown in Fig. 1. Cuttings were collected and planted in the field on April 30. They were then sprayed with $50 \mathrm{mg} / 1$ 6BAP ('BA-Ekizai', a 0.5\% 6-benzylaminopurine solution from Kumiai Chemical Industries Co., Ltd.) with $0.4 \%$ NAA ('Ruton' of $0.4 \% \alpha$-naphthl acetamide powder from Ishihara Sangyo Kaisha Ltd.) at the base before and after cutting in the field on April 30 and May 6 and 13. The percentage of rooted cuttings and of bud sprouting were investigated for every 18 plants on June 30.

\section{Effects of Number of Spray Applications of 6BAP on} Sprouting and Growth of Stumps (Experiment 2)

Buds 20-40 cm above the ground were removed on April 30. 6BAP was applied at $50 \mathrm{mg} / 1$ onto the stumps once (April 30), twice (April 30 and May 6) or three times (April 30, May 6 


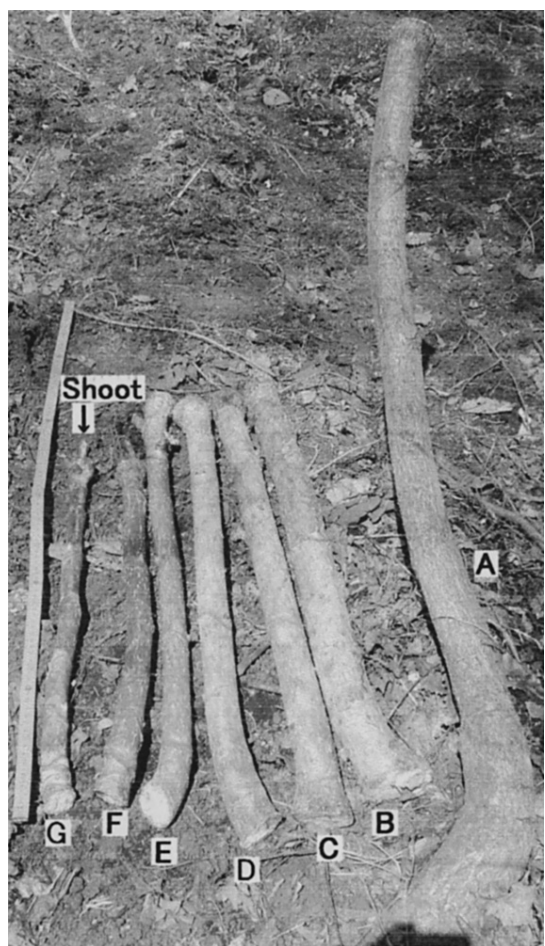

Fig. 1. Six cuttings and a stump from a seven-year-old $A$. elata tree. A, stump (stem grown seven years); B, a cutting from the bottom; C-F, cuttings from the middle; $\mathrm{G}$, a cutting from the top. The scale on the left indicates $1 \mathrm{~m}$.

and May 13). Bud sprouting, sprout elongation (length of the longest sprout on a tree) and leaf numbers (foliate leaf numbers of the longest sprout on a tree) were investigated for every 18 stumps on the same day as in experiment 1 . The percentage of buds $1 \mathrm{~cm}$ or more in diameter on stumps were investigated for all regenerated buds for all treatments.

4. Effects of the Concentration of 6BAP on Sprouting and Growth of Sprouts on Trunks with the Apical Shoot Removed (Experiment 3)

Three to four-year-old plants without branching were used for

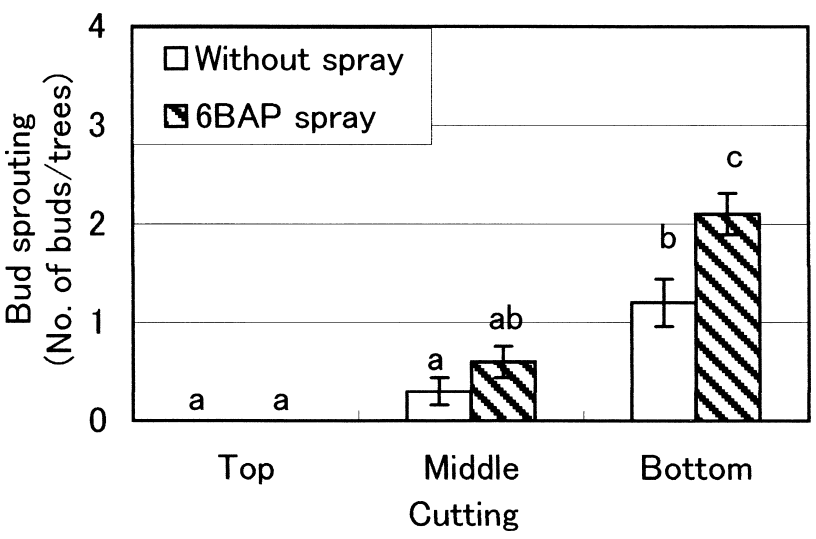

Fig. 2. Effects of 6BAP applications on bud sprouting with lignified cuttings of $A$. elata. Top, cuttings were collected from the top of the tree; Middle, cuttings were collected from the middle of the tree; Bottom, cuttings were collected from the bottom of the tree. Vertical bars show standard errors $(\mathrm{n}=18)$. Different letters indicate a significant difference $(p<0.05)$ according to the Tukey test.

this experiment. 6BAP was sprayed onto whole plants after the removal of apical buds. Plants were sprayed three times with 10,50 or $200 \mathrm{mg} / \mathrm{l}$ of 6BAP. Whole cuttings were sprayed with the 6BAP solutions on April 30, May 6 and May 13. Bud sprouting, sprout elongation and number of leaves were investigated in 18 plants on June 30 . The percentages of buds $1 \mathrm{~cm}$ or more in diameter on stumps were investigated for all regenerated buds on the same day.

\section{RESULTS}

\section{Effects of 6BAP on Sprouting of Lignified Cuttings}

Bud sprouting on lignified cuttings from the middle and bottom of the tree was promoted by $50 \mathrm{mg} / 1$ of $6 \mathrm{BAP}$ in the field (Fig. 2). An average of 2.1 buds formed when $50 \mathrm{mg} / 1$ of 6BAP was sprayed onto cuttings from the bottom of a tree. An average of 1.2 buds sprouted without 6BAP. On large-diameter lignified cuttings from seven-year-old plants, buds sprouted after the application of 6BAP (Fig. 3A). Only 44\% of cuttings from the bottom took root after 6BAP was applied
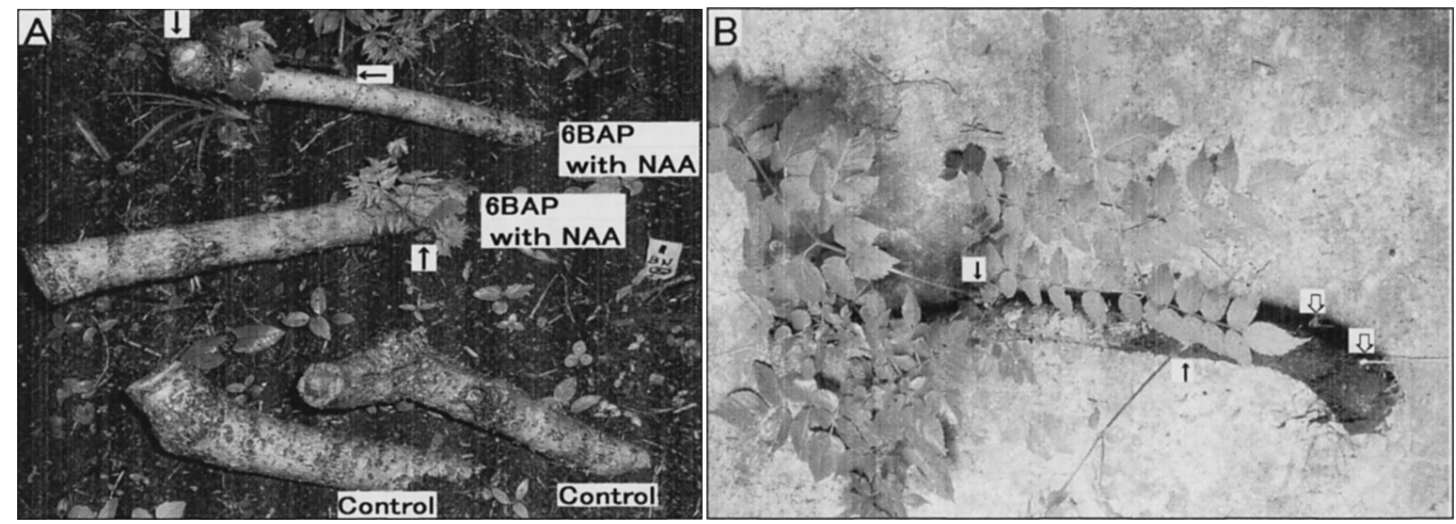

Fig. 3. Effects of $50 \mathrm{mg} / 1$ 6BAP spray applications with $0.4 \%$ NAA in A. elata. A: Bud sprouting $(\downarrow)$ on lignified cuttings from the bottom of the tree. B: Sprouting $(\downarrow)$ and rooting $(\downarrow)$ on cuttings. 


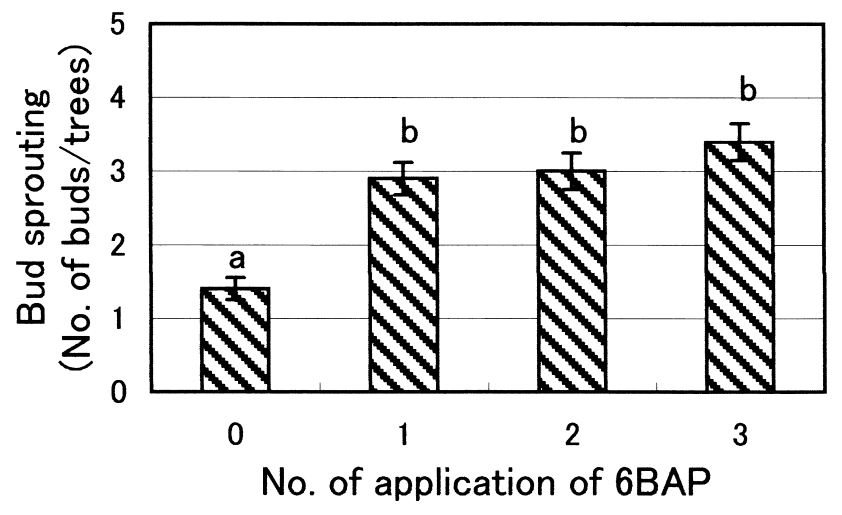

Fig. 4. Effects of the number of 6BAP applications on bud sprouting on stumps of A. elata. 0, control; 1, sprayed on April 30; 2, sprayed on April 30 and May 6; 3, sprayed on April 30, May 6 and May 13. Vertical bars show standard errors $(n=18)$. Different letters indicate a significant difference $(p<0.05)$ according to the Tukey test.

with NAA (Fig. 3B). However, lignified cuttings taken from the top did not develop roots. About $70 \%$ of sprouts were 1 $\mathrm{cm}$ or more in diameter with and without treatment with 6BAP.

\section{Effects of Number of Applications of 6BAP on Sprout- ing and Growth of Stumps}

More buds sprouted on the stumps treated with one to three applications of $50 \mathrm{mg} / 1$ 6BAP than on those not sprayed at all (Fig. 4). An average of 2.9-3.4 sprouts formed with one to three applications of $50 \mathrm{mg} / \mathrm{l}$ of 6BAP on stumps and an average of 1.4 without 6BAP. Three times more buds sprouted following two 6BAP applications. There were no significant differences between the effect of one to three applications. Sprout lengths and leaf numbers were decreased on stumps given three applications of $50 \mathrm{mg} / 1$ of $6 \mathrm{BAP}$ compared to those treated once, a twice, or not at all (Table 1). About three new buds sprouted when $50 \mathrm{mg} / 1$ of 6BAP was applied to large diameter stumps of six to seven-year-old trees (Fig. 5). Some $74 \%$ of buds were $1 \mathrm{~cm}$ or more in diameter following

Table 1. Effects of number of applications of 6BAP on the growth of sprouts on stumps in A. elata

\begin{tabular}{cccc}
\hline $\begin{array}{c}\text { Times } \\
\text { of 6BAP } \\
\text { spray }\end{array}$ & $\begin{array}{c}\text { Sprout } \\
\text { length } \\
(\mathrm{cm})\end{array}$ & $\begin{array}{c}\text { No. of } \\
\text { leaf }\end{array}$ & $\begin{array}{c}\% \text { of } 1 \mathrm{~cm} \text { or } \\
\text { more diameter } \\
\text { of sprout }(\%)\end{array}$ \\
\hline 0 & $17.6 \mathrm{~b}^{\mathrm{a})}$ & $6.9 \mathrm{~b}$ & 88.0 \\
1 & $15.9 \mathrm{~b}$ & $6.1 \mathrm{~b}$ & 89.6 \\
2 & $16.8 \mathrm{~b}$ & $6.2 \mathrm{~b}$ & 74.1 \\
3 & $4.1 \mathrm{a}$ & $2.7 \mathrm{a}$ & 65.6 \\
\hline
\end{tabular}

a) Different letters indicate a significant difference $(p<0.05)$ with the Tukey test.

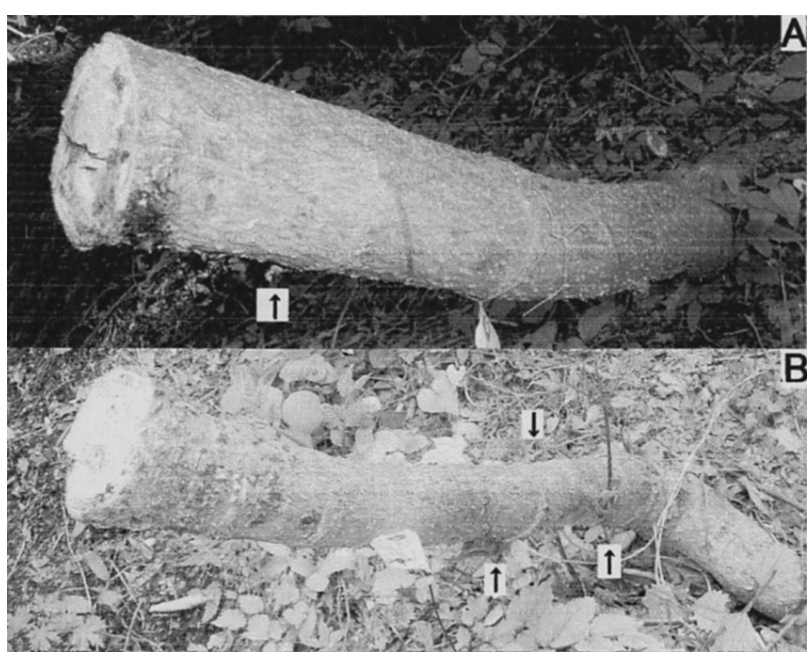

Fig. 5. Effects of 6BAP on bud sprouting $(\downarrow)$ on stumps in $A$. elata. A, without spraying; B, three applications with $50 \mathrm{mg} / \mathrm{l}$ of 6BAP.

two applications of $6 \mathrm{BAP}$ at $50 \mathrm{mg} / 1$ to stumps.

3. Effects of Concentration of $6 B A P$ on Sprouting and Growth of Sprouts on Trunks with the Apical Shoot Removed

More buds sprouted with the spray applications than without on trunks with the apical buds removed (Table 2). An average of 1.8 buds sprouted without 6BAP and 2.9-3.5 with 10-200 $\mathrm{mg} / \mathrm{l}$ of $6 \mathrm{BAP}$. There were no significant differences between bud sprouting, sprout elongation and number of leaves at 10 , 50 and $200 \mathrm{mg} / \mathrm{l}$.

\section{DISCUSSION}

Cytokinins promote the growth of leaves and lateral buds in plants. ${ }^{5,7)}$ Cytokinins also promote the development of secondary xylem in pea and growth of lateral buds from xylem in tobacco. ${ }^{8,9)}$ Also, it is easy to promote adventitious buds with plant callus using auxin with a high concentration of cy-

Table 2. Effects of 6BAP concentrations on the growth of sprouts on trunks in A. elata after removal of apical buds

\begin{tabular}{rcccc}
\hline $\begin{array}{c}\text { BBAP } \\
(\mathrm{mg} / \mathrm{l})\end{array}$ & $\begin{array}{c}\text { Bud } \\
\text { sprouting } \\
(\text { No. of } \\
\text { sprouts/trees })\end{array}$ & $\begin{array}{c}\text { Sprout } \\
\text { length } \\
(\mathrm{cm})\end{array}$ & $\begin{array}{c}\text { No. of } \\
\text { leaf }\end{array}$ & $\begin{array}{c}\text { \% of } 1 \mathrm{~cm} \\
\text { or more } \\
\text { diameter of } \\
\text { sprout }(\%)\end{array}$ \\
\hline 0 & $1.8 \mathrm{a}^{\mathrm{a})}$ & $4.8 \mathrm{a}$ & $2.9 \mathrm{a}$ & 77.8 \\
10 & $2.9 \mathrm{~b}$ & $5.0 \mathrm{a}$ & $3.0 \mathrm{a}$ & 83.3 \\
50 & $3.5 \mathrm{~b}$ & $5.1 \mathrm{a}$ & $3.1 \mathrm{a}$ & 72.2 \\
200 & $3.3 \mathrm{~b}$ & $4.7 \mathrm{a}$ & $2.8 \mathrm{a}$ & 66.7 \\
\hline
\end{tabular}

a) Different letters indicate significant difference $(p<0.05)$ with the Tukey test. 
tokinin. ${ }^{10,11)}$ The percentage of bud sprouting on plants without buds increased with 6BAP treatment in A. elata. ${ }^{1)}$ Bud sprouting was promoted by 6BAP sprayed on cuttings, stumps and subterranean stems in A. elata in this study. A cytokinin, '6BAP' promotes the growth of axillary buds in Citrus unshu trees. ${ }^{12-14)}$ Apical dominance is inhibited by the cytokinin because it accumulates in the vessels of roots when the apical bud is removed. ${ }^{15,16)}$ Therefore, it is thought that application of 6BAP promotes epinasity and is useful for lateral bud sprouting of arboreous plants like A. elata because it has a developed xylem.

Buds can be harvested when the tops of stems with a bud before sprout growth are harvested and grown in a greenhouse in $A$. elata. ${ }^{1)}$ Buds sprouted on treatment with 6BAP not only from tops of stems but also from five to six cut stems from $2-3 \mathrm{~m}$ tall plants. Therefore, it is thought that cuttings from all parts of tall plants can be used for the harvesting of shoots. Bud numbers were 2-4 on stumps sprayed with 6BAP. Therefore, it is thought that if a mature tree is cut down, the amount of harvesting work will decrease because it will become a dwarf plant and 6BAP will increase sprout harvest from stumps the following year. It will be possible to increase bud harvesting with $50 \mathrm{mg} / \mathrm{l}$ of 6BAP for whole trees after removal of the apical bud, because application of 6BAP promotes branching in A. elata trees.

6BAP promoted bud sprouting on cuttings, stumps and trunks with the apical bud removed in A. elata.

\section{REFERENCES}

1) S. Yamaguchi, Y. Murakami and S. Jyoudou: Bull. Ehime Univ.
Forest. 38, 37-44 (2000) (in Japanese).

2) T. Tanaka: "Tanaka's Cyclopedia of Edible Plants of the World," Keigaku-sha Ltd., Tokyo, p. 924, 1976.

3) N. Yoshizawa., H. Shimizu, Y. Wakita, S. Yokota and T. Idei: Bull. Utsunomiya Univ. Forest. 30, 19-26 (1994).

4) F. Skoog and D. J. Armstrong: Annu. Rev. Plant Physiol. 20, 359-384 (1970).

5) H. Sugiura: J. Pestic. Sci. 29, 308-312 (2004).

6) M. Wickson and K. V. Thimann: Physiol. Plant. 11, 62-74 (1958).

7) S. Kuraishi and F. S. Okumura: Bot. Mag. Tokyo, 69, 300-306 (1956)

8) H. P. Sorkin, S. N. Mathur and K. V. Thimann: Plant Physiol. 49, 444-454 (1962)

9) J. I. Medford, R. Horgan, Z. El-Sawi and H. J. Klee: Plant Cell. 1, 403-413 (1989).

10) D. D. Earle and R. W. Langhans: J. Am. Soc. Hort. Sci. 99, 128131 (1974).

11) T. Murashige, M. Serpa and J. B. Jones: Hort. Sci. 9, 175-180 (1974).

12) X. R. Zhu and K. Matsumoto: Acta Hortic. 230, 419-426 (1988).

13) X. R. Zhu, K. Matsumoto and M. Shiraishi: J. Jpn. Soc. Hort. Sci. 57, 578-584 (1989) (in Japanese).

14) H. Inoue, Y. Kami and F. Fujiwara: Res. Bull. Ehime-Ken. Agri. Res. Sta. 17, 7-17 (2003) (in Japanese).

15) F. Bangerth: Planta 194, 439-442 (1994).

16) C. J. Li, E. Guevara, J. Herrera and F. Bangerth: Physiol. Plant. 94, 465-469 (1995). 